\title{
FENIKS EN PAULOWNIA: EEN KAMERSCHERM VAN W.F.L. GRAAF VAN BYLANDT
}

De Chinese mythische vogel die op dit scherm te zien is, wordt bij ons aangeduid als een feniks (afb. 1). Daar lijkt hij natuurlijk wel een beetje op, maar de Chinese en ook de daarvan afgeleide Japanse variant van dit hemelse wezen zijn beslist geen feniksen. Echter, bij gebrek aan beter en omdat het nu eenmaal makkelijker leest dan telkens de Japanse aanduiding hôô, vindt u het hier toch maar zo vertaald.

Zoals vele dingen in Japan komt deze mythische vogel uit China, waar hij onder andere rijdier is voor taoïstische onsterfelijken en andere hemelse wezens, zoals bijvoorbeeld de Koningin-moeder van het Westen. Eigenlijk zijn er twee verschillende dieren die bijna inwisselbaar zijn: de Rode Vogel van het Zuiden (zhu niao) en de fenghuang, vertaald als feniks. ${ }^{1}$ Ze komen allebei in verschillende vormen voor en zijn wat uiterlijk betreft niet van elkaar te scheiden. Waarschijnlijk overlappen ze inhoudelijk ook. De Rode Vogel wordt in ieder geval sinds de $7^{\mathfrak{e}}$ eeuw voor Christus afgebeeld als een van de vier dieren van de windrichtingen; alleen in die combinatie weten we dan zeker dat het om de Rode Vogel gaat. Hij gaat gepaard met de Groene Draak van het Oosten, de Witte Tijger van het Westen en de Zwarte Krijger van het Noorden, een schildpad verstrengeld met een slang. De fenghuang is een andere hemelse vogel, met een overdadig verenkleed. In latere tijden komt de feniks vaak samen met de draak voor: die combinatie staat voor de keizerin en keizer. De keizerin en vrouwelijke leden van de hofhouding droegen bijvoorbeeld een hoed waarop een aantal gouden feniksen was bevestigd. In Japan is die keizerlijke connotatie overgenomen en is hij een vast paar met de paulownia imperialis, de boom waarvan de bladeren en bloemen het wapen van de keizerlijke familie vormen.

In de Japanse schilderkunst komt een enkel zesdelig kamerscherm niet vaak voor. Gezien de voorstelling is dit scherm waarschijnlijk het linkerdeel geweest van een paar, met het beekje doorlopend op de rechterhelft, die ook versierd zal zijn geweest met een of meer feniksen en paulownia. Er is een bekend paar schermen met vergelijkbare voorstelling van Kano Tan'yu (16021674) waar dit $19^{\mathrm{c}}$-eeuwse exemplaar mogelijk op teruggrijpt. ${ }^{2}$ Het is mogelijk dat het is geschilderd tegen het midden van de $19^{c}$ eeuw, toen de gemoederen in Japan opliepen over de onvermijdelijke openstelling van Japan. Tegenstanders van buitenlandse bemoeienis en ook degenen die het shogun-regime om andere redenen beu waren, schaarden zich in hun verzet tegen het shogunaat onder de keizerlijke vlag. Kamerschermen als deze zouden wel eens gemaakt kunnen zijn als interieur-uithangbord van het politieke standpunt van de eigenaar. 


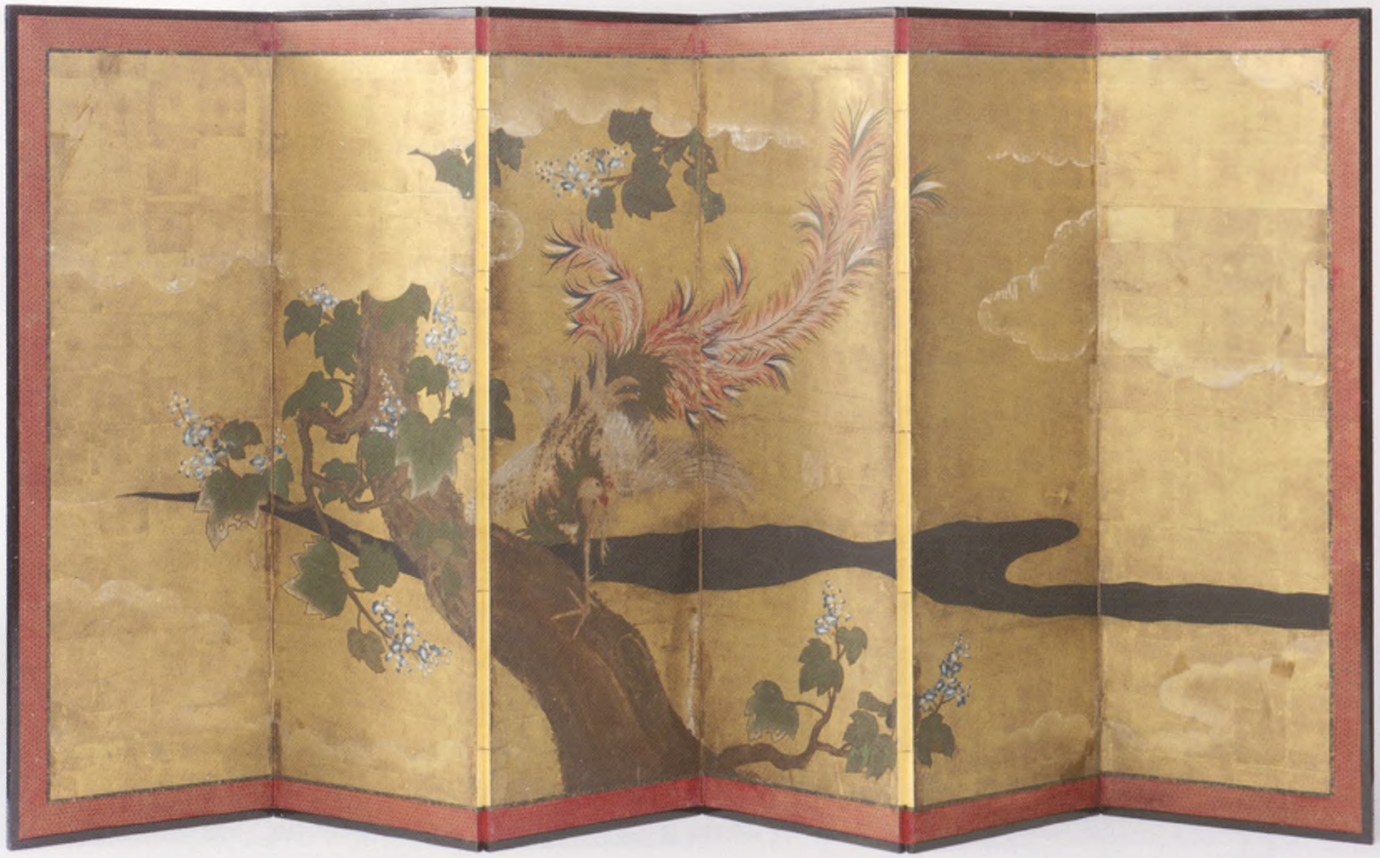

Afbeelding 1 Zesdelig kamerscherm, inkt, kleuren en goud op papier, Japan, $19^{\circ}$ eeuw. Schenking mr. W.F.L. graaf van Bylandt in 1986, Rijksmuseum Amsterdam, collectie VVAK, AK-MAK-1405 (detail op pag. וu)

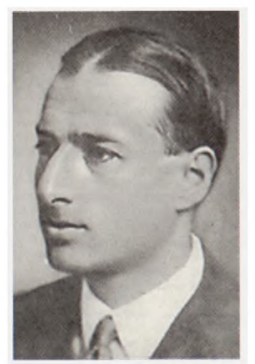

Afbeelding 2 Willem Frederik Lodewijk graaf van Bylandt (1896-1990)
Ook bij de schenking een eeuw later is er een politiek randje aan het verhaal. Het scherm werd in 1953 in bruikleen gegeven door een prominente diplomaat, mr. W.F.L. graaf van Bylandt (1896-1990). ${ }^{3}$ Van Bylandt had zich in de jaren voor de Tweede Wereldoorlog ontwikkeld als een veelbelovend lid van de diplomatieke dienst; ook de binnen de Vereniging bekende Ernst Heldring liet zich positief over hem uit. In 1936 schrijft hij: 'Onder het jonge personeel zijn er enkelen die veel beloven, o.a. van Bylandt te Parijs. ${ }^{4}$ In de Tweede Wereldoorlog werd van Bylandt door de Nederlandse regering in ballingschap belast met het buitenlands beleid: uiteraard een zware post, waarbij vooral de plek van Nederland in Azië zijn aandacht vergde. Behalve de relatie met China (waar hij al in 1926 drie maanden gestationeerd was geweest) hield hij zich toen bezig met de gang van zaken in NederlandsIndië: in de periode tot de Japanse bezetting in maart 1942, maar ook na de afloop van de oorlog. Vanaf november 1945 was hij in Jakarta betrokken bij de onderhandelingen die leidden tot het akkoord van Linggadjati, dat de staatkundige verhoudingen van Nederland met de pas uitgeroepen Republiek Indonesië poogde te regelen. Na een post in Rome keerde hij van 1952 tot 1956 terug naar Indonesië om zich als Hoge Commissaris nogmaals te wijden aan de vrijwel onmogelijke taak om de moeizame relaties tussen beide landen tot een normale internationale verhouding om te smeden.

Het was in deze periode dat het Japanse kamerscherm naar de Vereniging kwam. Uit de correspondentie wordt duidelijk dat Van Bylandt in 1952 advies vroeg over restauratie van het scherm aan Herman Visser (wellicht op suggestie van Heldring?), die de vaste restaurator $v_{f_{0}}$ de vereniging aanbeval ${ }_{45 \mathrm{AM}}$ F.A.J. Smoorenburg. Nog voordat de restauratie voltooid was, schreef Van access 
Bylandt aan Visser dat hij 'het zou waarderen indien het museum dit scherm in bruikleen zou willen aanvaarden, althans gedurende den tijd dat ik in Djakarta zal vertoeven, waarheen ik de volgende week vertrek.' Het scherm kwam in april 1953 naar het Rijksmuseum en zou daar blijven; Van Bylandt besloot in 1986 het bruikleen om te zetten in een schenking. ${ }^{5}$

Hoewel het natuurlijk heel goed mogelijk is dat Van Bylandt het stuk bij een Europese antiquair kocht, is het ook goed denkbaar dat hij het in Indonesië verwierf. Als we ons zouden toestaan voor de vuist weg te spreken, zouden we het scherm kunnen zien in het bezit van iemand van hogere rang in het Japanse leger, die er zijn liefde voor het keizershuis mee wilde uitdrukken en die het meenam naar Indonesië om er zijn vertrekken mee in te richten. Misschien moet een conservator zijn fantasie niet zo de vrije hand laten en gaat het veel te ver om van het kamerscherm getuige van de $20^{\mathrm{e}}$-eeuwse geschiedenis te willen maken. Wellicht moeten we het laten bij het prijzen van een getalenteerd diplomaat met een goed hart, die in een hectische periode uit zijn carrière nog tijd vond om een goede bestemming te zoeken voor een interessant kamerscherm.

\section{Noten}

1. Zie J. Rawson, Chinese ornament: The Lotus and the Dragon, Londen, 1984, pp. 90 , 91, 99-107.

2. In de collectie van het Suntory Museum of Art in Tokyo. Zie bijvoorbeeld Biombo: Japan Heritage as Legend of Gold (tent.cat. Suntory Museum of Art en Osaka Municipal Museum of Art), 2007, pp. 110, 111.

3. A.E. Kersten, in: J. Bosmans e.a. (red.), Biografisch Woordenboek van Nederland. Deel V, Den Haag, 2001, pp. 67-68.

4. J. de Vries (red.), Herinneringen en dagboek van Ernst Heldring (1871-1954), Utrecht, 1970, p. 1159.

5. Correspondentie, bewaard in het archief VVAK (in het Rijksmuseum Amsterdam). 